\title{
Isolation of Anti Ageing Molecules Secreted by Human Gingival Stem Cells. Protection of Collagen and Elastic Networks
}

\author{
Hafida Chérifi 1,2,3,4, Adrien Naveau ${ }^{1,2,3,4}$, Ludwig Loison Robert1,2,3,4, Bruno Gogly 1,2,3,4 \\ ${ }^{1}$ Dental Department, A. Chenevier-H. Mondor Hospital, Créteil, France \\ ${ }^{2}$ UMR S872, Université Paris Descartes, Sorbonne Paris Cité, France \\ ${ }^{3}$ UMR S872, Centre de Recherche des Cordeliers, Université Pierre et Marie Curie, Paris, France \\ ${ }^{4}$ INSERM U872, Paris, France \\ Email: bruno.gogly@ach.aphp.fr
}

Received 4 April 2014; revised 3 May 2014; accepted 11 May 2014

Copyright (C) 2014 by authors and Scientific Research Publishing Inc.

This work is licensed under the Creative Commons Attribution International License (CC BY).

http://creativecommons.org/licenses/by/4.0/

(c) (i) Open Access

\begin{abstract}
Skin aging results in an imbalance between synthesis and degradation of the extracellular matrix. Overproduction of degradative enzymes (MMPs) and oxygen free radicals during chronological and photo-induced aging leads a degradation of the network and elastic skin collagen. Our previous work demonstrated that a culture supernatant of gingival stem cells had anti-aging activities in vitro, ex vivo and in vivo in humans. However, this culture medium is very complex and currently not responding to the European cosmetics regulation. After the analysis of the culture medium we have isolated 4 molecules interesting in terms of skin anti-aging activity: TIMP1, Selenium, Folic Acid and Glycin (TSAG). After the study of the most efficiency concentration of each molecule, the composition of TSAG is tested on irradiated UVA human dermal fibroblast and human skin. TSAG preserves the elastin and collagen network and inhibits the MMP1, MMP3 and MMP9 activities. The advantage of this mimetic solution of stem cells is to be stable, easily reproducible and non-human origin. The outlook for cosmetology seems interesting.
\end{abstract}

\section{Keywords}

Human Gingival Stem Cell, MMPs, Collagen, Elastin

\section{Introduction}

Skin aging is associated with an increase in the number and depth of wrinkles as a result of the degradation of macromolecules of the dermis with collagen and elastin. In the dermis, the overproduction of MMPs that is in- 
volved in chronological aging and induces by solar radiation is stimulated by the overproduction of oxygen free radicals [1]. This is particularly true in the sun-exposed areas, such as facial skin; where the deleterious effects of ultraviolet radiation: collagen imperfect synthesis, skin pigmentation and solar elastolysis result in degradation of skin elastic network. Our previous work has shown that the culture supernatant of human gingival fibroblasts, that have exceptional healing capacity, inhibits the degradation of human skin subjected to UV exposure [2]. Since this publication in 2010 we have isolated a subpopulation of human gingival stem cells (hGSC) [3]. These cells are extensively studied and have very different perspectives in human cell therapy [4]. However, the culture supernatant of these cells is very complex and also has deleterious components for positive matrix remodeling including MMPs and pro-inflammatory cytokines. Currently, European regulations cosmetology no longer allows the use of products of human origin. The use of human products may cause contaminations. Moreover the composition of a cell culture supernatant may vary depending on the cell line. It seems interesting to realize that a combination of active product that is reproducible, stable and contains the most interesting of these supernatant molecules in terms of skin anti-aging activity. We therefore cultured human gingival fibroblasts and human gingival stem cells to study the composition of the culture media and observe any differences in the culture medium. After a careful analysis of the cell culture supernatant, four molecules found in the supernatant have a major activity in skin aging. These molecules are known for their antioxidant, anti-free radicals and anti MMPs. They stimulate the synthesis of macromolecules including collagen and elastin. These molecules are selenium, folic acid, glycin and the TIMP1. We found in our experiments the optimal concentrations of four molecules in terms of inhibition of MMP activity and protection of collagen and elastic networks. The active substance is a mixture of TIMP1, Selenium, Folic Acid and Glycin was called TSAG. TSAG product has been tested in vitro on skin fibroblasts and ex vivo human skin biopsies irradiated with ultraviolet A.

\section{Material and Methods}

\subsection{In Vitro Experiences}

\subsubsection{Obtaining Cells (hGF, hGSC and hDF)}

Five Human gingival fibroblast (hGF) cultures were obtained from gingival explants of healthy patients with no periodontitis history. Five Human dermal fibroblast (hDF) cultures were obtained from skin biopsies of normal subjects after aesthetic or reconstructive surgery (the same biopsies as those used for organotypic studies). All patients (20 - 30 years old) gave their informed consent according to the Helsinki Declaration (1975) and denied having recently taken drugs that could affect connective tissue metabolism. The tissue samples were divided into two parts: one for a histologic analysis and the other for a cell culture. The serial gum tissue sections were stained with hematoxylin and eosin for assessing of the tissue quality and the absence of inflammatory infiltrates in the gingiva. Only the histological healthy tissue was used for experiments.

The primary cultures were established in $25 \mathrm{~cm}^{2}$ culture flasks from explants and used from passage 3 to 5 . The monolayer cultures were maintained during 3 weeks in Dulbecco's modified Eagle's medium (DMEM, Invitrogen-Life Technologies, Cergy Pontoise, France) with Knock-Out Serum Replacement (SFm, Serum Free medium) (KOSR, Invitrogen-Life Technologies) at $37^{\circ} \mathrm{C}$ in a $5 \% \mathrm{CO}_{2}$ and $95 \% \mathrm{O}_{2}$ atmosphere. The Serum-free medium (SFm) developed in our study consisted of DMEM supplemented with 20\% KOSR. The SFm was optimized with $1 \mathrm{mM}$ L-Glutamine and 1\% non-essential amino acids. The SFm required supplementation with basic Fibroblast Growth Factor (b-FGF, 1 ng/mL, human recombinant; Invitrogen-Life Technologies) for long term culture, and insulin ( $5 \mu \mathrm{g} / \mathrm{mL}$, human recombinant; Invitrogen-Life Technologies) for facilitating cell cycle progression [5].

The cell culture medium was changed every 72 hours. After the first passage, cells were routinely maintained either in SFM.

\subsubsection{Obtention and Characterization of HGSC Are Largely Described in Our Publication [3]}

In short, after two weeks, the gingival fibroblasts were trypsinised and single cell suspension were seeded at very low concentration (concentration $\leq 100$ cellules $/ \mathrm{cm}^{2}$; medium DMEM $10 \%$ of FCS with $50 \mu \mathrm{g} / \mathrm{mL}$ of ascorbic acid) after having checked the absence of aggregates of cells to avoid false-positives. After 14 days of culture, the colony-forming units of fibroblasts (CFU-F) were counted under a microscope. Only aggregates of more than 50 cells are regarded as colonies. The CFU-F was then transferred and gathered into a $25 \mathrm{~cm}^{2}$ flask and cultivated in DMEM $10 \%$ supplemented with $50 \mu \mathrm{g} / \mathrm{mL}$ of ascorbic acid. The characterization of the hGSC 
was confirmed by osteoblastic cellular differentiation carried out using specific media of induction. Differentiation in osteoblasts was induced in a medium DMEM including $10 \%$ FCS, $50 \mu \mathrm{g} / \mathrm{mL}$ of ascorbic acid, $100 \mathrm{nM}$ dexamethasone and $20 \mathrm{mM} \beta$-glycerophosphate [3].

\subsubsection{Preparation of $\mathrm{hGF}$ and $\mathrm{hGSC}$ Conditioned Medium (hGFm and hGSCm)}

The culture medium from $75 \mathrm{~cm}^{2}$ flasks of confluent hGF or hGSC cultures was discarded. $24 \mathrm{~mL}$ of SFm was then added and retrieved 24 hours later. The conditioned medium was then freezed at $-80^{\circ} \mathrm{C}$ until analyse.

\subsubsection{Analysis of hGFm and hGSCm}

Analysis of cell culture supernatant is carried out by various medical laboratories using HPLC techniques, spectrometry, ELISA and biological techniques. The analysis can show the presence of four molecules that play a major role in skin aging: TIMP1, selenium, folic acid and glycine.

For to determine the concentration of TIMP1 of the future composition, a first series of experiments aimed for optimal inhibition of MMPs activity induced by UVA irradiation of human dermal fibroblasts (classical model of aging in vitro [2]).

\subsubsection{Inhibition of MMPs Secreted by the Irradiated hDF (hDFi) by UVA-Preparation of hDF}

Two 24-well plates (Nunc) of each culture were cultured with hDF from a $25 \mathrm{~cm}^{2}$ flask. When confluence is reached (75 000 cells per well), hDF plate is irradiated with UVA 15 Joules $/ \mathrm{cm}^{2}$ (hDFi) [2], the second plate is used as a control to verify the absence of MMP-9 in the absence of irradiation. The culture media are changed after irradiation. In the hDFi cultures the following solutions are added: PBS only in 4 wells ( $500 \mu \mathrm{L}$ per well), PBS $20 \mathrm{pg} / \mathrm{mL}$ TIMP1 in 4 wells (500 $\mu \mathrm{L}$ per well), PBS $80 \mathrm{pg} / \mathrm{mL}$ TIMP1 in 4 wells (500 $\mu \mathrm{L}$ per sinks), PBS $160 \mathrm{pg} / \mathrm{mL}$ TIMP1 in 4 wells (500 $\mu \mathrm{L}$ per well), PBS $320 \mathrm{pg} / \mathrm{mL}$ TIMP1 in 4 wells (500 $\mu \mathrm{L}$ per well). Culture media are then collected 24 hours later, aliquoted and stored at $-80^{\circ} \mathrm{C}$ for analysis of MMPs.

The optimum concentration of TIMP1 is also determined $(80 \mathrm{pg} / \mathrm{mL})$ and the solution TSAG is prepared.

\subsubsection{Preparation of the Active Solution TSAG: TIMP1/Selenium/Folic Acid/Glycine (TSAG)}

After to have determined the optimum concentration of TIMP1, 3 other molecular solutions are added at the same concentration as they are secreted by the "embryo-like" cells: selenium $(10 \mathrm{ng} / \mathrm{mL})$, folic acid $(4 \mu \mathrm{g} / \mathrm{mL})$ and glycine $(30 \mu \mathrm{g} / \mathrm{mL})$ (Table 1$)$.

\subsubsection{Anti MMPs Activity of TSAG Solution on hDFi}

hDFi 4 wells are grown $24 \mathrm{~h}$ with a solution of PBS + TSAG. After 24 hours the cell culture supernatant is analyzed.

\subsubsection{Protein Analysis of Cellular Culture Media}

MMP-1 (DMP100), MMP-3 (DMP300), MMP-9 (DMP900), TIMP-1 (DTM100), were analysed by ELISA (R\&D Systems) according to the recommendations of the manufacturer.

The statistical analysis was made using Wilcoxon and Mann-Whitney tests. Please note that the isoforms of these molecules are much conserved between the various species: it enabled the use of human ELISA kits for a human supernatant immunodetection.

\subsection{Organotypical ex Vivo Experiment}

Five human skin biopsies cultures were obtained from normal subjects after aesthetic or reconstructive surgery. All biopsies were rinsed with a Hank's solution. Each of the five skins samples was split up into fragments of 5 $\mathrm{mm}$ with a trocar, each fragment was weighed and UVA-irradiated or not at $15 \mathrm{Joules} / \mathrm{cm}^{2}\left(\mathrm{Si}_{15}\right)$ and then cultivated in a collagen with or without TSAG for seven days.

In a $10 \mathrm{~mL}$ Erlenmeyer, $6 \mathrm{~mL}$ of serum free medium (SFm) or $6 \mathrm{~mL}$ of SFm containing TSAG (see the paragraph in vitro cellular experiments), $3.4 \mathrm{~mL}$ of rat type I collagen (Jacques Boy Institute, $2 \mathrm{mg} / \mathrm{mL}$, ref: 207050257) and $600 \mu \mathrm{L}$ filtered $\mathrm{NaOH} 0.1 \mathrm{~N}$ (to neutralize the acid collagen solution) were mixed. Then a skin fragment was deposited in the prepared solution and carefully homogenized with the solution. Lastly, the whole was placed in a $60 \mathrm{~mm}$ Petri dish and in an incubator at $37^{\circ} \mathrm{C} / 5 \% \mathrm{CO}_{2}$. 
Table 1. Composition of the supernatant of HGF and HGSC in culture. The concentrations are in mg/L.

\begin{tabular}{|c|c|c|}
\hline \multirow{2}{*}{$\begin{array}{l}\text { Components } \\
\text { Amino acids }\end{array}$} & \multicolumn{2}{|c|}{ Concentration (mg/L) } \\
\hline & hGFm & hGSCm \\
\hline Glycine & 28 & 27 \\
\hline L-arginine hydrochloride & 79 & 79 \\
\hline L-cystine 2HCI & 56 & 55 \\
\hline L-glutamine & 540 & 532 \\
\hline L-histidine hydrochloride- $\mathrm{H}_{2} \mathrm{O}$ & 38 & 38 \\
\hline L-isoleucine & 99 & 92 \\
\hline L-leucine & 104 & 96 \\
\hline L-lysine hydrochloride & 135 & 134 \\
\hline L-methionine & 30 & 29 \\
\hline L-phenylalanine & 64 & 58 \\
\hline L-serine & 37 & 35 \\
\hline L-threonine & 84 & 76 \\
\hline L-tryptophan & 12 & 12 \\
\hline L-tyrosine & 66 & 62 \\
\hline L-valine & 94 & 90 \\
\hline \multicolumn{3}{|l|}{ Vitamins } \\
\hline Choline chloride & 4 & 3,8 \\
\hline D-calcium panthonetate & 4 & 3,8 \\
\hline Folic acid & 4 & 4 \\
\hline i-inositol & 7.2 & 7 \\
\hline Niacinamide & 4 & 3,5 \\
\hline Pyridoxine hydrochloride & 4 & 3,2 \\
\hline Riboflavin & 0.4 & 0,3 \\
\hline Thiamine hydrochloride & 4 & 3 \\
\hline \multicolumn{3}{|l|}{ Inorganic salts } \\
\hline Calcium chloride $\left(\mathrm{CaCl}_{2}-2 \mathrm{H}_{2} \mathrm{O}\right)$ & 260 & 245 \\
\hline Ferric nitrate $\left(\mathrm{Fe}\left(\mathrm{NO}_{3}\right)_{3}-9 \mathrm{H}_{2} \mathrm{O}\right)$ & 0.1 & 0,1 \\
\hline Magnesium sulfate $\left(\mathrm{MgSO}_{4}-7 \mathrm{H}_{2} \mathrm{O}\right)$ & 192 & 187 \\
\hline Potassium chloride (KCI) & 304 & 258 \\
\hline Sodium bicarbonate $\left(\mathrm{NaHCO}_{3}\right)$ & 3204 & 2468 \\
\hline Sodium chloride $(\mathrm{NaCI})$ & 5279 & 4981 \\
\hline Sodium phosphate monobasic $\left(\mathrm{NaH}_{2} \mathrm{PO}_{4}-2 \mathrm{H}_{2} \mathrm{O}\right)$ & 124 & 114 \\
\hline \multicolumn{3}{|l|}{ Other components } \\
\hline D-glucose (dextrose) & 3900 & 3820 \\
\hline Sodium pyruvate & 106 & 104 \\
\hline MMP1 & $24 \times 10^{-6}$ & $17 \times 10^{-6}$ \\
\hline MMP2 & $31 \times 10^{-6}$ & $24 \times 10^{-6}$ \\
\hline MMP3 & $21 \times 10^{-6}$ & $17 \times 10^{-6}$ \\
\hline TIMP1 & $86 \times 10^{-6}$ & $72 \times 10^{-6}$ \\
\hline TIMP2 & $68 \times 10^{-6}$ & $64 \times 10^{-6}$ \\
\hline IL1ß & $113 \times 10^{-6}$ & $94 \times 10^{-6}$ \\
\hline IL4 & $321 \times 10^{-6}$ & $221 \times 10^{-6}$ \\
\hline IL6 & $18 \times 10^{-6}$ & $18 \times 10^{-6}$ \\
\hline TGF $\beta$ & $412 \times 10^{-6}$ & $370 \times 10^{-6}$ \\
\hline \multicolumn{3}{|l|}{ Concentration of trace components } \\
\hline $\mathrm{Ag}^{+}$ & 0.00009 & 0.00001 \\
\hline $\mathrm{AI}^{3+}$ & 0.0001 & 0.0001 \\
\hline $\mathrm{Ba}^{2+}$ & 0.001 & 0.0006 \\
\hline $\mathrm{Cd}^{2+}$ & 0.005 & 0.0004 \\
\hline $\mathrm{Co}^{2+}$ & 0.0005 & 0.0005 \\
\hline $\mathrm{Cr}^{3+}$ & 0.00004 & 0.00003 \\
\hline $\mathrm{Ge}^{4+}$ & 0.0005 & 0.00005 \\
\hline $\mathrm{Se}^{4+}$ & 0.007 & 0.0075 \\
\hline $\mathrm{Br}^{3+}$ & 0.00006 & 0.00004 \\
\hline I & 0.0001 & 0.00009 \\
\hline $\mathrm{Mn}^{2+}$ & 0.00006 & 0.00006 \\
\hline F & 0.002 & 0.0015 \\
\hline $\mathrm{SI}^{4+}$ & 0.02 & 0.003 \\
\hline $\mathrm{V}^{5+}$ & 0.00038 & 0.00038 \\
\hline $\mathrm{Mo}^{6+}$ & 0.0007 & 0.0007 \\
\hline $\mathrm{NI}^{2+}$ & 0.00003 & 0.000024 \\
\hline $\mathrm{Rb}^{+}$ & 0.0008 & 0.0006 \\
\hline $\mathrm{Sn}^{2+}$ & 0.00003 & 0.00002 \\
\hline $\mathrm{Zr}^{4+}$ & 0.0001 & 0.0001 \\
\hline
\end{tabular}


Five control collagen lattices were cultivated without skin fragments, in order to test whether bioactive molecules within the collagen gel and the culture medium would contribute to the results.

The cultures were maintained for a week and analysed at day 1, 3 and 7. At each point of experimentation 3 $\mathrm{mL}$ of supernatant were collected and stored at $-80^{\circ} \mathrm{C}$ for further analysis of the secreted proteins.

\section{Histological Analysis by Computerized Image Analysis}

The skin biopsies (control at day 0 ) and their surrounding collagen lattices were collected at 7 days, rinsed with PBS $1 \times$ and fixed in Paraformaldehyde 4\%/PBS during 48 hours. They were then dehydrated with alcohol 70\%, then $95 \%$, then $100 \%$ and finally in a toluene before a paraffin inclusion. Sections $(7 \mu \mathrm{m})$ were stained using three different specific protocols.

Hemalun/eosin protocol: after rehydration, the sections were covered with hemalun during five minutes before using with tap water, then with eosin during 1 minute.

Sirius Red protocol (collagen network): after rehydration, the sections were covered with Sirius Red during 30 minutes. The quantification of collagen density was performed within 2 steps. Firstable, the color image was transformed into monochrome with a 255 level gray scale. Thereafter, we evaluated the relative number of pixels classified as red by adjusting the threshold permitting a binary analysis. The measurements were performed in three independent fields by slide.

Orcein protocol (elastin network): after partial rehydration (stopped with alcohol 95\%), the sections were immersed into an orcein solution during half an hour. A fast rinsing with alcohol 95\% (with 2 hydrochloric acid drops added) was then carried out. Slides were lastly rinsed with distilled water before dehydratation and final assembling. The elastin density was quantified similarly as the collagen density.

\section{Results}

1) Isolation and characterization of HGSC (Figure 1)

For each of the five cultures of gingival fibroblasts we isolated by the limiting dilution technique cell clones (Figure 1(a)). To verify that these clones were well made of HGSC we have oriented towards a pathway of osteoblast differentiation. We then proceeded to staining by Alizarin Red the bone material secreted by the osteoblasts (Figure 1(b)) [3]. The HGSC isolated and characterized were cultured in the same manner that hGF which they are derived.

2) Analysis and hGFm hGSCm (Table 1) (TSAG isolated molecules)

Culture media of $5 \mathrm{hGF}$ are mixed to achieve an average products secretion of five cellular cultures. A similar operation is performed with the 5 cultures of hGSC. Analysis of culture media of hGF and hGSC show little differences in composition. This first experiment shows that there are no significant differences between the secretions and hGF hGSC. For the following experiments hGSCm only are used.

3) Determination of the concentration of TIMP1 of TSAG on hDFi cultures: anti-metalloproteases activities (Figure 2)

After the hDF irradiation amount of MMP1 and MMP3 secreted by the cells are multiplied by 6 (respectively

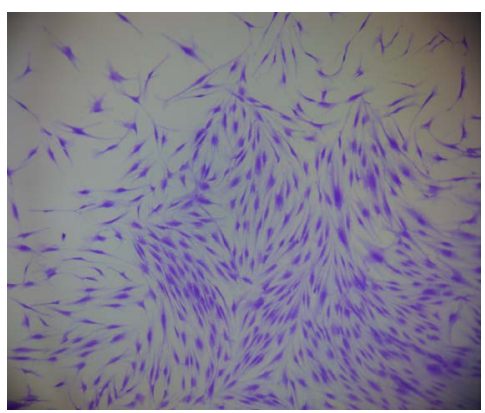

(a)

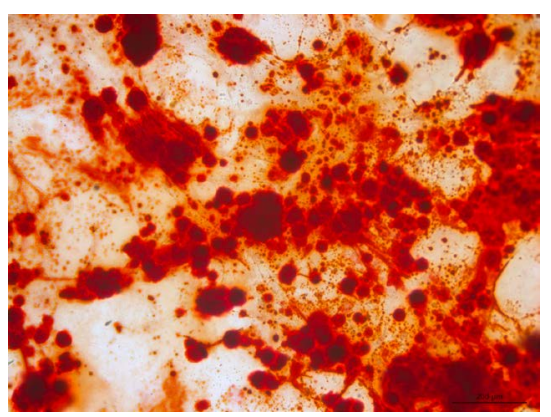

(b)

Figure 1. Isolation and characterization of hGSC. (a) Colony forming at low density of hGSC. The stem cells are colored with Trypan blue. (b) The osteogenic differentiation is characterized by the secretion of extra cellular mineral matrix colored with Alizarin red. 


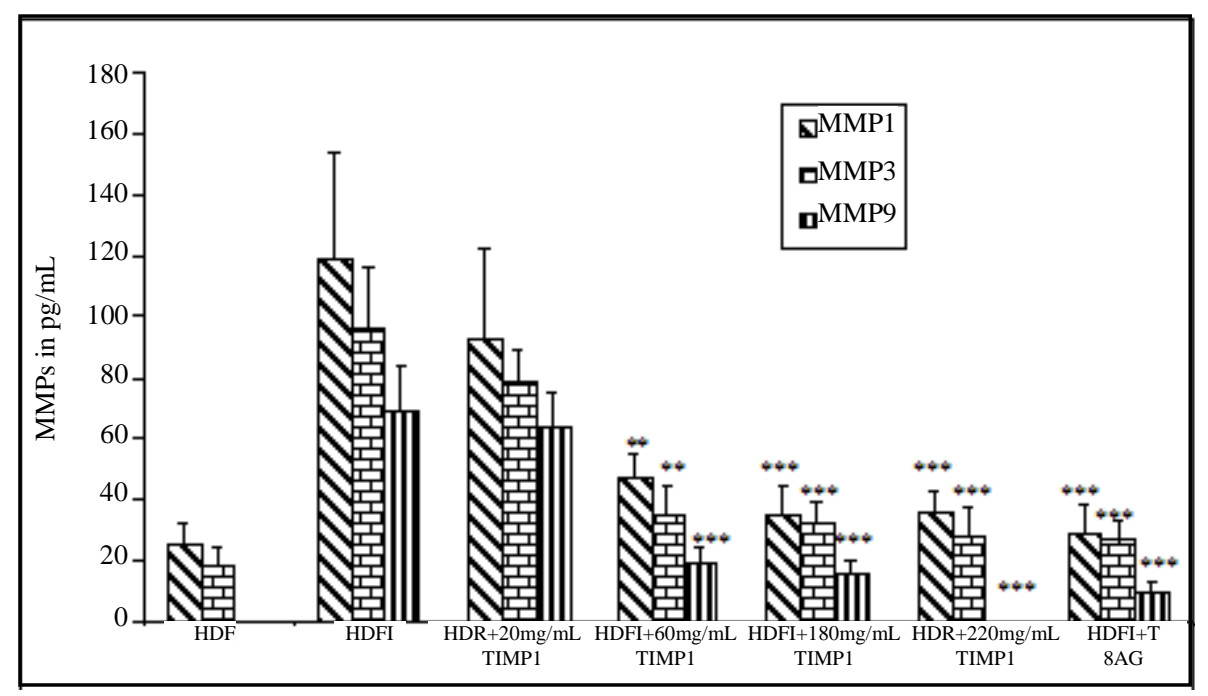

Figure 2. Determination of the optimal concentration of TIMP1 $(80 \mathrm{mg} / \mathrm{mL})$ for inhibition of MMPs secreted by the irradiated hDF (hDFi) by UVA. Effect of the composition of TSAG on hDFi.

25 and 18 to $119 \mathrm{pg} / \mathrm{mL}$ and $96 \mathrm{pg} / \mathrm{mL}$ ). The hDF cultures do not secrete MMP9, while after irradiation; the concentration of MMP9 is $69 \mathrm{pg} / \mathrm{mL}$. The addition of $20 \mathrm{pg} / \mathrm{mL}$ of TIMP1 in the culture medium of irradiated cells allows a non significant reduction of MMP activity. At $80 \mathrm{pg} / \mathrm{mL}$, TIMP1 induces a significant reduction of the activity of MMP1 (119 to $47 \mathrm{pg} / \mathrm{mL}, \mathrm{p}<0.05$ ), of MMP3 (96 to $35 \mathrm{pg} / \mathrm{mL}, \mathrm{p}<0.01$ ) and of MMP9 (69 to 19 $\mathrm{pg} / \mathrm{mL}, \mathrm{p}<0.01$ ). A $160 \mathrm{pg} / \mathrm{mL}$, TIMP1 inhibition of MMP activity is very similar to $80 \mathrm{pg} / \mathrm{mL}$. A TIMP1 320 $\mathrm{pg} / \mathrm{mL}$ of inhibition of the activity of MMP1 and MMP3 is the same as the concentration of $80 \mathrm{pg} / \mathrm{mL}$ and MMP9 activity becomes undetectable like to the cultures of unirradiated skin cells. The concentration of 80 $\mathrm{pg} / \mathrm{mL}$ of TIMP1 is the most effective on the activity of MMPs. This concentration of TIMP1 is used for the composition of the active product TSAG. The 3 others molecules are added at the same concentration as they are secreted by the "embryo-like" cells hGCS: selenium $(10 \mathrm{ng} / \mathrm{mL})$, folic acid $(4 \mu \mathrm{g} / \mathrm{mL})$ and glycine $(30 \mu \mathrm{g} / \mathrm{mL})$. The product composition TSAG is thus determined. On irradiated cells, TSAG composition greatly reduces the activity of MMP-1 (119 to $41 \mathrm{pg} / \mathrm{mL}$ ), MMP3 (96 to $34 \mathrm{pg} / \mathrm{mL}$ ) and MMP9 (69 to $12 \mathrm{pg} / \mathrm{mL}$ ) and statistically highly significant $(\mathrm{p}<0.01)$.

4) Effect of TSAG on the activity of MMP-1, 3, 9 secreted by irradiated human skin (Figure 3)

The solution inhibits TSAG the activity of MMPs secreted by human skin biopsies irradiated with UVA. After 48 hours of cultures, MMP1 activity decreases by 35\% (p < 0.01), that of MMP3 by $42 \%(\mathrm{p}<0.05)$ and MMP9 activity decreases by $52 \%(\mathrm{p}<0.01)$.

5) Protection of the elastic an collagen network by TSAG on irradiated human skin (Figure 4)

After 7 days of culture, the solution TSAG limits the degradation of the elastic and collagen networks of the irradiated skin. However, this observed inhibition does not completely inhibit the effect of the irradiation. Thus the loss of the elastic network of the irradiated skin was 58\% compared to the control and only $17 \%$ in the presence of TSAG (Figure 4(a)). In a comparable manner, the loss of collagen network of the irradiated skin was 33\% compared to the control and only 9\% in the presence of TSAG (Figure 4(b)).

\section{Discussion}

Our previous work demonstrated that a culture supernatant of neurectodermic stem cells had anti-aging activities in vitro, ex vivo and in vivo in humans: preservation of elastic networks collagen and inhibiting the activity of MMP's responsible for the degradation of the dermal extracellular matrix. However, this culture medium is very complex and currently not responding to the European cosmetics regulation, which prohibits the use of products of human origin. It seems that interesting to make a composition that is reproducible and that reproduces the molecules of this supernatant the most interesting in terms of skin anti-aging activity. 4 molecules found in the culture medium are known for their antioxidant effects, anti-free radical, anti MMPs and enter the synthesis of 


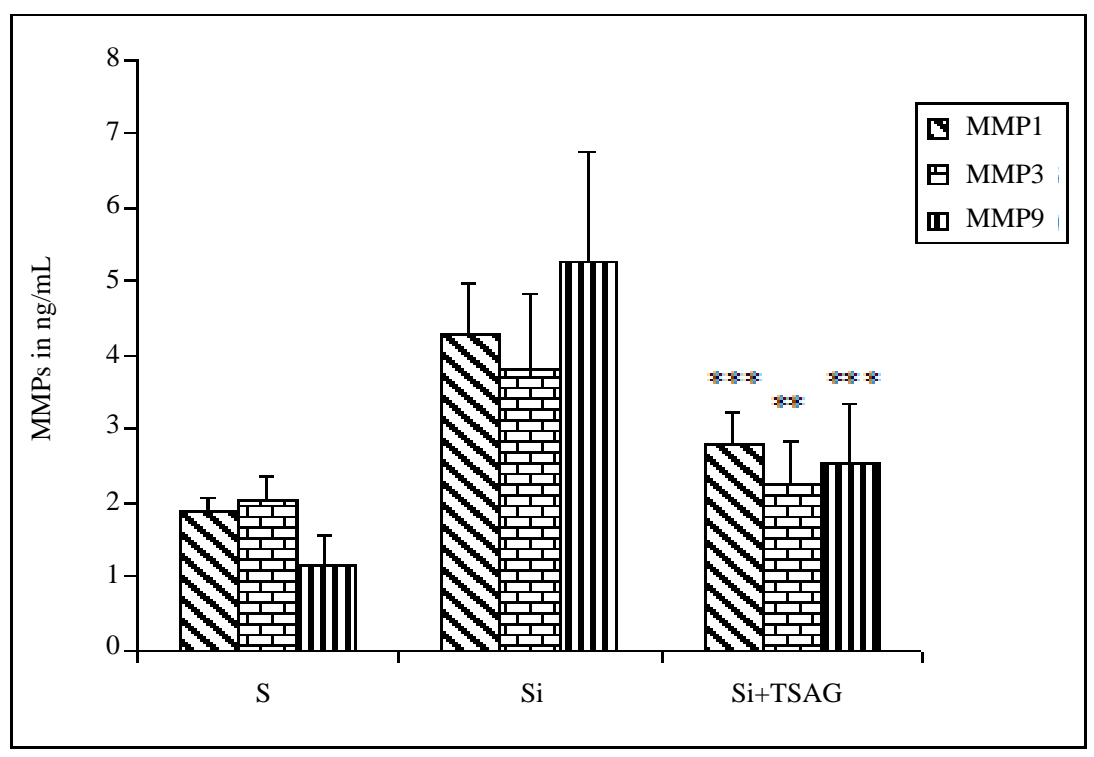

Figure 3. Evaluation of the anti MMPs activity of TSAG on human skin irradiated in organotypic cultures.

macromolecules including collagen and elastin: the TIMP1, selenium, and folic acid Glycine (TSAG). We therefore performed a molecular composition of these 4 products by determining the optimal concentration of each. TSAG product thus prepared showed skin anti-aging activities of particular interest. Each component of TSAG is individually known as active cosmetic product. The originality of this work is to combine these components whose concentrations are similar to those produced by human stem cells and thus achieve a stable, reproducible active composition and meet regulatory requirements.

The TMP1 is the tissue inhibitor of key enzymes responsible for the destruction of the dermal extracellular matrix including MMP1, MMP3 and MMP9 [6]. These three enzymes are involved in the degradation of collagen, elastin, proteoglycans and glycoproteins. These enzymes are overexpressed by dermal fibroblasts under UV stimulation and oxygen free radicals [7]. Many substances which inhibit MMPs are currently used against skin aging. They help to inhibit the degradation of the extracellular matrix induced by the sun and oxygen free radicals. The TIMP1, an inhibitor of these enzymes is a natural protector of the skin extracellular matrix.

Selenium is found in trace amounts in the body, where it belongs to the family of trace elements. By 1969, many epidemiological studies have demonstrated the preventive action of selenium in cancer development. As such, the selenium is not an antioxidant: in fact it is unable to interact with activated oxygen species (AOS) as are vitamins $\mathrm{C}$ and $\mathrm{E}$ and beta-carotene. Selenium is an essential micronutrient required for at least two types of enzymes involved in defence against oxidative stress [8] [9]. These enzymes, glutathione peroxidase and thioredoxin reductase, are an important part of the cell's defences against oxidative stress and are essential to maintaining a stable redox balance. In enzymes, selenium is present as selenocysteine [10]. The selenium has a protective effect against the damage induced by UV whose cytotoxicity [11] [12] the oxidation of the DNA, the expression of interleukin 10 [13] and lipid peroxidation [14]. Oral intake of sodium selenite protects against UV-induced erythema in mice against the appearance of skin pigmentation [15] and the development of skin cancers [16] [17]. His skin anti-aging effect is related is its powerful indirect antioxidant effect [18] [19]. Its use in cosmetology appears to be very promising.

Folic acid is a vitamin that belongs to the group of vitamin $B$. This water soluble vitamin is also known as vitamin B9, vitamin $\mathrm{M}$ or folacin rarely. Remember that the human body is unable to synthesize vitamins and therefore they must be supplied through diet or supplementation. As a precursor to methionin (essential amino acid which the body can not synthesize), folic acid plays a role in the synthesis of DNA and RNA and thus in cell renewal. The role of folic acid is essential when a cell in the body requires a rapid renewal (blood cells, stomach, intestine, mouth, skin). Topical application of folic acid significantly improves the in vivo skin firmness. In vitro, the secretion of collagen by dermal fibroblasts is stimulated by acid folic, suggesting that the in vivo anti-wrinkle effects are based on the stimulation of collagen metabolism [20]. 

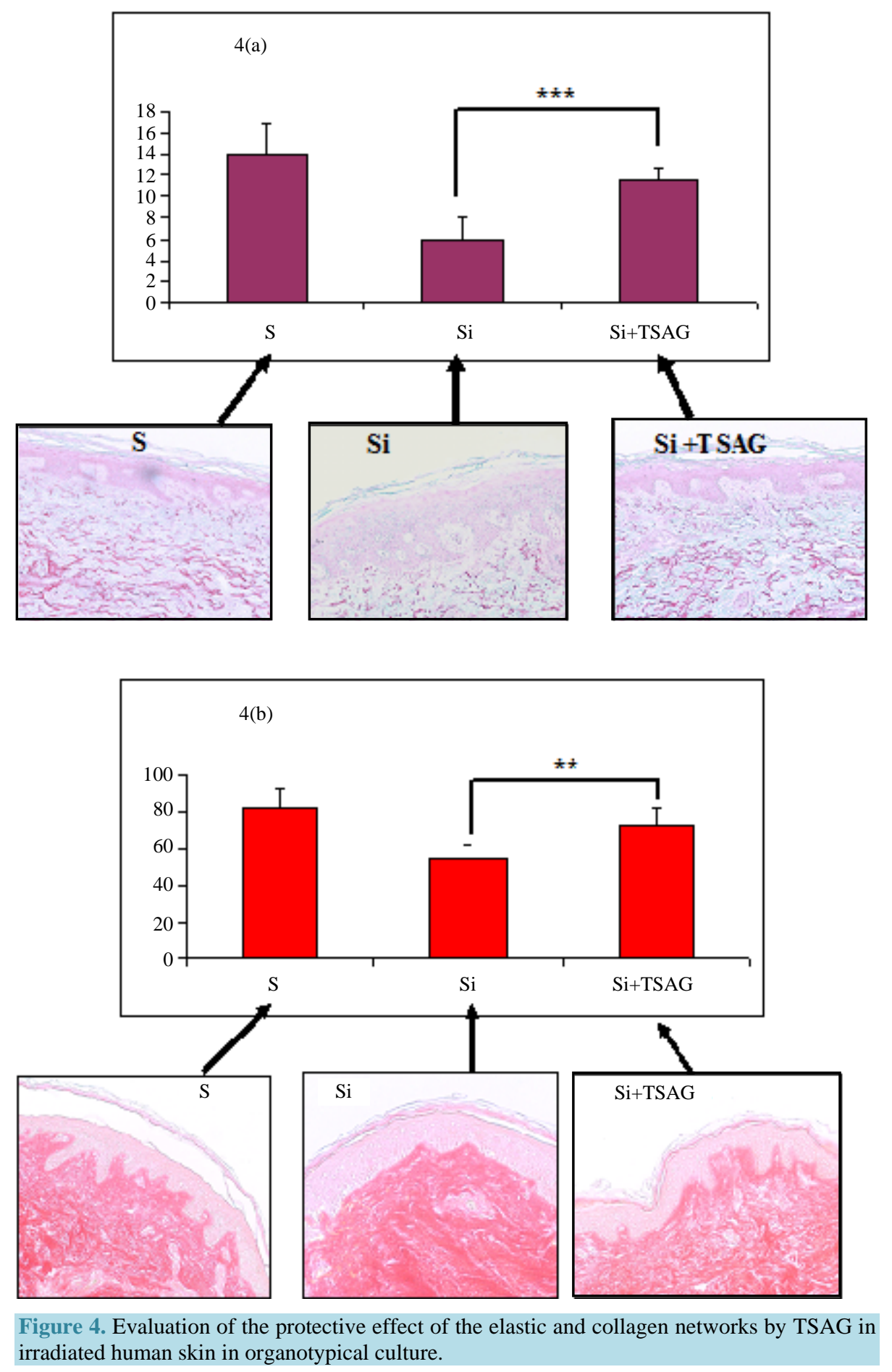

Glycine, formerly called glycine or amino acetic acid, is a non-essential amino acid $\alpha$ said because it can be produced by the body from other amino acids. This is the simplest amino acid and represents more than $30 \%$ of the amino acids used in the formation of fibrillar collagens including collagen I, collagen main skin. Collagen I is composed of a sequence of amino acid triplet Gly-X-Y, and its synthesis is essential for skin repair. Degradation is major in the phenomena of aging and is responsible for the appearance of wrinkles [2] [21]. Glycine is also the main constituent of elastin with prolin. Collagen and elastin are essential to maintaining the mechanical properties of the skin and target molecules are many anti aging assets. 
The originality of this research is associated 4 molecules of skin network in a new molecular composition whose concentrations are those secretions from stem cells in culture. The molecular composition is perfectly reproducible and does not have the disadvantages of a variable cell secretion and which contains many deleterious molecules skin (inflammatory cytokines, proteolytic enzymes, possible contamination). The composition TSAG shows in vitro and ex vivo a major protective effect of elastic and collagen network and inhibits the enzymes responsible for the degradation of the entire dermal extracellular matrix.

\section{Conclusion}

In the first study published in 2011, we showed that the supernatant of cultures of gingival stem cells exhibited anti-aging activity in humans. Currently the European regulation on cosmetic products prohibits the use of human origin substances. We have studied the composition of the culture supernatant to determine the molecules responsible for the anti-aging activity. Four molecules which were widely used in cosmetics are present in the culture medium. We therefore carried out a solution with precise concentrations of these four molecules and tested this solution on human skin models in vitro and ex vivo. It appears that this composition called TSAG outperforms the supernatant of stem cells from our models of skin aging. The advantage of the solution is to be stable, easily reproducible and non-human origin. The outlook for cosmetology seems interesting and will be evaluated on an anti wrinkle 6-month study in humans.

\section{References}

[1] Rafferty, T.S., Green, M.H., Lowe, J.E., Arlett, C., Hunter, J.A., Beckett, G.J. and McKenzie, R.C. (2003) Effects of Selenium Compounds on Induction of DNA Damage by Broadband Ultraviolet Radiation in Human Keratinocytes. British Journal of Dermatology, 148, 1001-1009. http://dx.doi.org/10.1046/j.1365-2133.2003.05267.x

[2] Gogly, B., Ferré, F., Cherifi, H., Naveau, A. and Fournier, B. (2011) Inhibition of Elastin and Collagen Networks Degradation in Human Skin by Gingival Fibroblast. In Vitro, ex Vivo and in Vivo Studies. Journal of Cosmetics, Dermatological Sciences and Applications, 1, 4-14.

[3] Fournier, B., Ferré, F., Couty, L., Lataillade, J.J., Gourven, M., Naveau, A., Coulom, B., Lafont, A. and Gogly, B. (2010) Multipotent Progenitor Cells in Gingival Connective Tissue. Tissue Engineering Part A, 16, 2891-2899. http://dx.doi.org/10.1089/ten.tea.2009.0796

[4] Fournier, B., Larjava, H. and Hakkinen, L. (2013) Gingiva as a Source of Stem Cells with Therapeutic Potential. Stem Cells and Development, 22, 3157-3177. http://dx.doi.org/10.1089/scd.2013.0015

[5] Naveau, A., Lataillade, J.J., Fournier, B.P., Couty, L., Prat, M., Ferré, F.C., Gourven, M., Durand, E., Coulomb, B., Lafont, A. and Gogly, B. (2010) Phenotypic Study of Human Gingival Fibroblasts in a Medium Enriched with Platelet Lysate. Journal of Periodontology, 82, 632-641. http://dx.doi.org/10.1902/jop.2010.100179

[6] Hornebeck, W. (2003) Down-Regulation of Tissue Inhibitor of Matrix Metalloprotease-1 (TIMP-1) in Aged Human Skin Contributes to Matrix Degradation and Impaired Cell Growth and Survival. Pathologie Biologie, 51, 569-573. http://dx.doi.org/10.1016/j.patbio.2003.09.003

[7] Rittié, L. and Fisher, G.J. (2002) UV-Light-Induced Signal Cascades and Skin Aging. Ageing Research Reviews, 1, 705-720. http://dx.doi.org/10.1016/S1568-1637(02)00024-7

[8] Emonet-Piccardi, N., Richard, M.J., Ravanat, J.L., Signorini, N., Cadet, J. and Béani, J.C. (1998) Protective Effects of Antioxidants against UVA-Induced DNA Damage in Human Skin Fibroblasts in Culture. Free Radical Research, 29, 307-313. http://dx.doi.org/10.1080/10715769800300341

[9] McKenzie, R.C. (2000) Selenium, Ultraviolet Radiation and the Skin. Clinical and Experimental Dermatology, 25, 631-636. http://dx.doi.org/10.1046/j.1365-2230.2000.00725.x

[10] Stadtman, T.C. (2000) Selenium Biochemistry. Mammalian Selenoenzymes. Annals of the New York Academy of Sciences, 899, 399-402. http://dx.doi.org/10.1111/j.1749-6632.2000.tb06203.x

[11] Emonet, N., Leccia, M.T., Favier, A., Beani, J.C. and Richard, M.J. (1997) Thiols and Selenium: Protective Effect on Human Skin Fibroblasts Exposed to UVA Radiation. Journal of Photochemistry and Photobiology B, 40, 84-90. http://dx.doi.org/10.1016/S1011-1344(97)00041-9

[12] Rafferty, T.S., McKenzie, R.C., Hunter, J.A., Howie, A.F., Arthur, J.R., Nicol, F. and Beckett, G.J. (1998) Differential Expression of Selenoproteins by Human Skin Cells and Protection by Selenium from UVB-Radiation-Induced Cell Death. Biochemical Journal, 332, 231-236.

[13] Rafferty, T.S., Walker, C., Hunter, J.A., Beckett, G.J. and McKenzie, R.C. (2002) Inhibition of Ultraviolet B Radiation-Induced Interleukin 10 Expression in Murine Keratinocytes Byselenium Compounds. British Journal of Dermato- 
logy, 146, 485-489. http://dx.doi.org/10.1046/j.1365-2133.2002.04586.x

[14] Moysan, A., Morlière, P., Marquis, I., Richard, A. and Dubertret, L. (1995) Effects of Selenium on UVA-Induced Lipid Peroxidation in Cultured Human Skin Fibroblasts. Skin Pharmacology and Physiology, 8, 139-148. http://dx.doi.org/10.1159/000211337

[15] Thorling, E.B., Overvad, K. and Bjerring, P. (1983) Oral Selenium Inhibits Skin Reactions to UV Light in Hairless Mice. Acta Pathologica et Microbiologica Scandinavica A, 91, 81-83.

[16] Overvad, K. (1998) Selenium and Cancer. Bibliotheca Nutritio et Dieta, 54, 141-149.

[17] Reid, M.E., Duffield-Lillico, A.J., Slate, E., Natarajan, N., Turnbull, B., Jacobs, E., Combs Jr., G.F., Alberts, D.S., Clark, L.C. and Marshall, J.R. (2008) The Nutritional Prevention of Cancer: 400 mcg per Day Selenium Treatment. Nutrition and Cancer, 60, 155-163. http://dx.doi.org/10.1080/01635580701684856

[18] Pinnell, S.R. (2003) Cutaneous Photodamage, Oxidative Stress, and Topical Antioxidant Protection. Journal of the American Academy of Dermatology, 48, 1-19. http://dx.doi.org/10.1067/mjd.2003.16

[19] Puizina-Ivić, N., Mirić, L., Carija, A., Karlica, D. and Marasović, D. (2010) Modern Approach to Topical Treatment of Aging Skin. Collegium Antropologicum, 34, 1145-1153.

[20] Fischer, F., Achterberg, V., März, A., Puschmann, S., Rahn, C.D., Lutz, V., Krüger, A., Schwengler, H., Jaspers, S., Koop, U., Blatt, T., Wenck, H. and Gallinat, S. (2011) Folic Acid and Creatine Improve the Firmness of Human Skin in Vivo. Journal of Cosmetic Dermatology, 10, 15-23. http://dx.doi.org/10.1111/j.1473-2165.2010.00543.x

[21] Pickart, L. (2008) The Human Tri-Peptide GHK and Tissue Remodeling. Journal of Biomaterials Science, Polymer Edition, 19, 969-988. http://dx.doi.org/10.1163/156856208784909435 